\title{
Predição in silico de epítopos antigênicos para produção de uma vacina humana contra leishmaniose visceral
}

Por meio de análises in silico, procurou-se identificar e selecionar epítopos de Leishmania infantum potencialmente capazes de disparar resposta imunogênica para elaboração de uma vacina comercial contra a leishmaniose visceral humana. Realizou-se a seleção de sequências para obtenção de um banco de dados específico e, posteriormente, analisou-se a similaridade genética com complexo de espécies causadoras de Leishmaniose Visceral (LV). Foram selecionadas sequências de interesse de L. infantum. Em seguida, fez-se a predição de estrutura secundária das sequências proteicas e a obtenção de epítopos reconhecidos por célula B juntamente com sua predição de afinidade de epítopos por MHC de classe II. Após esse processo, fez-se a modelagem de estrutura terciaria das proteínas para análise do modelo proteico gerado. Observou-se, pela análise in silico, as proteínas desejáveis, e a partir de suas estruturas tridimensionais, foi possível chegar na predição dos epítopos conformacionais. Destaca-se, ainda, que a confiabilidade destes resultados carece de experimentos em bancadas.

Palavras-chave: Bioinformática; Imunógeno; Leishmania infantum.

\section{In silico prediction of antigenic epitopes for the production of a human visceral leishmaniasis vaccine}

\begin{abstract}
Through in silico analyzes, we sought to identify and select Leishmania infantum epitopes potentially capable of triggering an immunogenic response to develop a commercial vaccine against human visceral leishmaniasis. Sequences were selected to obtain a specific database and, afterwards, the genetic similarity with a complex of species causing Visceral Leishmaniasis (LV) was analyzed. Sequences of interest of L. infantum were selected. Secondary structure prediction of protein sequences and B cell recognized epitopes were predicted along with their prediction of MHC class II epitope affinity. After this process, the tertiary protein structure modeling was performed to analyze the generated protein model. By in silico analysis, the desirable proteins were observed, and from their three-dimensional structures, it was possible to predict the conformational epitopes. It is also noteworthy that the reliability of these results require experiments on benches.
\end{abstract}

Keywords: Bioinformatics; Immunogen; Leishmania infantum.

Topic: Imunologia

Reviewed anonymously in the process of blind peer.
Received: $\mathbf{2 3 / 1 1 / 2 0 1 8}$

Approved: 25/01/2019
Lafayete Modesto de Macedo Junior Universidade Federal de Lavras, Brasil http://lattes.cnpq.br/8164518870362447 lafayete.macedo@ufla.br

\section{Tuane Ferreira Melo}

Universidade Federal de Lavras, Brasil

http://lattes.cnpq.br/7003071033672294

tuaneferreiramelo@gmail.com

Ana Paula Peconick

Universidade Federal de Lavras, Brasil

http://lattes.cnpq.br/4999231814389477

anappeconick@ufla.br
Referencing this:

MODESTO JUNIOR, L. M.; MELO, T. F.; PECONICK, A. P.. O uso do laser não ablativo no rejuvenescimento facial. Scire Salutis, v.9, n.1, p.6271, 2019. DOI: http://doi.org/10.6008/CBPC2236-9600.2019.001.0008 


\section{INTRODUÇÃO}

Em 1990, iniciou-se o Projeto Genoma Humano marcando o início da Era Genômica, que segundo Prosdocimi (2002), foi propiciada devido aos avanços científicos na biologia molecular e a evolução dos sequenciadores de código genético. Isso gerou um grande volume de informações referentes não apenas ao Genoma Humano, mas que também, se estendeu a diversos organismos (SANTOS et al., 2003).

Em meio à massiva quantidade de informação obtida, surge a necessidade de buscar interpretações, identificando a função dos genes bem como sua relação na estrutura e funcionamento dos organismos. Binneck (2004) propôs uma metodologia que permitia organizar, manipular, analisar e interpretar esse grande volume de informações em tempo hábil a partir dos bancos genômicos de forma a atender as exigências do meio científico.

Nesse sentido Arbex et al. (2006), Lesk (2007) e Prosdocimi (2002) concordam que a bioinformática teve papel de destaque, pois além de suprir a necessidade vigente, permaneceu em constante evolução, ampliando a gama de ferramentas e recursos computacionais disponíveis ao meio científico, e de acordo com Prosdocimi et el. (2004) e Verli (2014), este destaque foi alavancado pela facilitação do acesso à internet, otimização dos recursos computacionais (hardwares e softwares) e não requerer altos investimentos financeiros para sua utilização. As ferramentas de bioinformática buscam respostas através de algoritmos computacionais que fazem o alinhamento das sequências e traçam similaridades gerando inferências biológicas como: filogenia, estrutura de proteínas, função de domínios proteicos, comparações entre genomas (intra e/ou interespecíficos).

Diante das vantagens apresentadas, estes recursos mostram-se promissores em pesquisas biomédicas. Outrossim, as pesquisas biomédicas são dispendiosas no quesito tempo e recursos financeiros porque a partir das análises in silico é possível selecionar e excluir elementos de acordo com sua relevância para a pesquisa de interesse. Portanto, diminuem o número de elementos candidatos aos testes in vivo que demandam maior tempo e investimento (ARAUJO, 2008; TEUFEL, 2006).

No Brasil, a Agenda Nacional de Prioridades de Pesquisa em Saúde (ANPPS) determina atenção prioritária às doenças negligenciadas que inclui: dengue, Doença de Chagas, esquistossomose, hanseníase, leishmaniose, malária e tuberculose. Este estudo terá enfoque na leishmaniose, que atualmente carece de métodos diagnósticos com maior confiabilidade e especificidade de modo a diminuir as possibilidades de reação cruzada com outras doenças causadas por parasitos da família Trypanosomatidae (FREIRE et al., 2009), disponibilização de novas drogas eficazes no tratamento e identificação de epítopos com capacidades imunogênicas para o desenvolvimento de vacinas (SANTOS et al., 2013).

A bioinformática trouxe avanços nas áreas genômicas e proteômicas tornando-se uma metodologia útil no desenvolvimento de vacinas por meio dos métodos de vacinologia reversa e vacinas gênicas (PINTO et al., 2011). Dessa forma, o trabalho de análises in silico de sequências de Leishmania infantum buscou-se em bancos de dados genômicos, baseando-se em similaridade genética, a seleção de epítopos antigênicos potencialmente capazes de disparar resposta imunogênica ao se ativar linfócitos B humanos e produzir 
células de memória. Ao atender tais perspectivas, é possível elaborar uma vacina comercial humana contra a leishmaniose visceral.

\section{MATERIAIS E MÉTODOS}

Buscou-se nucleotídeos, ESTs, e genes de proteínas relevantes no GenBank $^{T M}$, utilizando-se o filtro para a espécie Leishmania infantum JPCM5 (taxid:435248) de modo a obter-se um banco de dados específico de sequências para análise. A partir do banco de dados específico foi realizado um alinhamento megablast contra dados genômicos de um complexo de espécies causadoras da leishmaniose visceral (LV) (taxid:38574). Posteriormente obteve-se similaridades entre as sequências comparadas, separando-as através de filtros do próprio GenBank ${ }^{\mathrm{TM}}$ as que mostraram similaridade significante ou alta similaridade (superior a 94\%).

Após agrupamento das sequências do complexo causador de LV em similaridade significante ou alta, estas foram comparadas com informações de um banco de dados específico contendo o genoma da $L$. infantum, o GeneDB. Realizou-se um alinhamento TBLASTX para verificar quais sequências apareciam conservadas em comum entre os dados do complexo de espécies causadores da LV (obtidas no GenBank ${ }^{\mathrm{TM}}$, taxid:38574) e os dados de $L$. infantum presentes no GeneDB. Por meio das sequências que obtiveram similaridade relevante, selecionou-se quais proteínas seriam submetidas para a predição da estrutura secundária das proteínas através da ferramenta PHD, retornando como resultados quais trechos da(s) sequência(s) apresentam alfa-hélice, fita estendida ou randômica além de loops e alças.

As proteínas selecionadas também foram submetidas à predição de epítopos reconhecidos por linfócitos B humano pelo banco de dados do IEDB Analysis Resource, por meio de algoritmos que calculam: hidrofilicidade, antigenicidade, flexibilidade e acessibilidade. Os epítopos de seleção foram testados quanto a afinidade de se ligarem a células de MHC-II de humanos utilizando a ferramenta NetMHCII do disponibilizado por Center of Biological Sequence Analysis (CBS).

Para as sequencias proteicas de interesse usou-se a ferramenta SWISS-MODEL. Dessa maneira, obteve-se a estrutura dimensional das proteínas (quando possível, algumas não reconhecem homologia) e obtenção dos resultados em arquivo de formato PDB. Para avaliação dos modelos proteicos gerados utilizouse a ferramenta Procheck disponibilizada em PDBsum_EBI, a fim de analisar a qualidade destes modelos.

\section{RESULTADOS}

A busca de sequências de proteínas relevantes realizada no GenBank ${ }^{\mathrm{TM}}$ para a Leishmania infantum JPCM5 (taxid:435248) retornou: ESTs pesquisadas com as palavras-chave: Leishmania chagasi (13.678 itens), Leishmania Infantum (14.025 itens ), MSP Leishmania (197 itens), antigen leishmania (11 itens), A2 leishmania (350 itens), elongation factor 2 leishmania (6 itens), S-adenosylhomocysteine hydrolase leishmania (2 itens), enolase leishmania (463 itens), 14-3-3 protein-like protein leishmania (182 itens), L-PSP leishmania (176 itens),reiske iron-sulfur protein precursor leishmania (19 itens), GTP-binding protein Rab1 leishmania (189 itens), peroxiredoxin leishmania (585 itens), HSP70 leishmania (2623 itens), co-chaperone 
grpe leishmania (243 itens), kmp11 leishmania (63 itens), PapLE22 leishmania (1 item), CpA leishmania (97 itens), CpB leishmania (186 itens).

Além desses, genes pesquisados com as palavras-chave: leishmania chagasi (8 itens), leishmania infantum (13.852 itens), elongation factor 2 leishmania (339 itens), MSP leishmania (26 itens), antigen leishmania (352 itens), a2 leishmania (41 itens), S-adenosylhomocystein hydrolase leishmania (8 itens), enolase leishmania (14 itens), 14-3-3 protein-like-protein leishmania (22), metalopeptidase leishmania (85 itens), L-PSP leishmania (7 itens), reiske iron-sulfur protein precursor leishmania ( 6 itens), GTP-binding protein Rab1 leishmania (31 itens), tryparedoxine leishmania (70 itens), peroxiredoxin leishmania (29 itens), HSP70 leishmania (256 itens), co-chaperone grpe leishmania (11 itens), kmp11 leishmania (18 itens), PapLE22 leishmania (7 itens), cpA leishmania (4 itens), cpB leishmania (16 itens).

Por meio da seleção de sequências específicas, houve a formação do banco de dados mais restrito, que contém dados de proteínas com potencial de carregar epítopos imunogênicos. A proteína MSP é uma proteína de superfície relacionada à virulência da Leishmania e inibienzimas formadoras do fagolisossoma; proteína A2 é predominante nas formas amastigotas e conferem a sobrevivência em altas temperaturas no interior do hospedeiro; elongation factor 2 envolvida na tradução e elongação da cadeia polipeptídica no ribossomo; S-adenosylhomocysteine hydrolase leishmania inibidor competitivo de processos intracelulares de metilação e fator de virulência.

Enolase atua na transcrição, migração de células, ativação de metalo-proteases e receptor de plasminogênio; 14-3-3 protein-like protein leishmania controla metabolismo, controle da expressão gênica, fatores de transcrição, resposta a stress, atividade apoptótica e morte celular; metalopeptidase leishmania conhecido como fator de virulência em Leishmania major e Leishmania mexicana; L-PSP leishmania atua em conjunto com a metalopeptidase com função da sobrevivência nas células do hospedeiro; reiske iron-sulfur protein precursor leishmania participa no processo de sinalização para programação de morte celular do hospedeiro e atividade oxiredutase e ubiguitinação no citocromo-c; GTP-binding protein Rab1 leishmania atua no controle e tráfego da secreção de proteínas do parasito.

Em continuidade, tryparedoxine leishmania protege contra atividades oxidativas de resposta do hospedeiro e encontra-se em maior volume nas espécies mais infectantes; peroxiredoxin função similar e em conjunto com a tryparedoxine e também possui papel na diferenciação celular e detoxificação celular; HSP70 atua em resposta a choque térmico, regula crescimento, desenvolvimento e diferenciação celular e sua ausência leva a diminuição na replicação e na virulência, co-chaperone grpe componente do complexo de translocação de peptídeos de membrana de mitocôndrias e enovelamento de proteínas junto a chaperonas.

Kmp-11 proteína de membrana da ordem Kinetoplastida, com função da infectividade e virulência, expressa em menor concentração nas amastigotas e em maior concentração nas promastigotas, confere diminuição na virulência por meio de bloqueio realizado por anticorpos monoclonais anti-KMP-11; PapLE22 proteína nuclear de promastigota, na presença de anticorpos específicos leva a redução de parasitos circulantes em hospedeiro; Cpa e Cpb em organismos que tiveram infecção por Leishmania possuem anticorpos anti-Cpa e anti-CpB sugerindo ser alvo importante de resposta imunológica. 
Partindo-se das sequências de interesse contidas no banco de dados específico, se comparou os alinhamentos entre as sequencias da L. infantum e o complexo de espécies causadoras de LV. Verificou-se quais se mostravam conservadas indicando proteínas que possivelmente estejam envolvidas no processo de infecção por parasitos causadores da doença, que poderão apresentar epítopos imunodominantes para utilização em testes de respostas imunogênica ao interagir com linfócitos B.

Por meio da similaridade retornada com o algoritmo BLAST foram obtidos os seguintes números de sequência com similaridade significante e alta similaridade, respectivamente: GP63 (91 e 18), A2 (49 e 21), tryparedoxin (9 e 3), peroxiredoxin (24 e 14), HSP70 (1230 e 164), cystein peptidase (17 e 11), papLe22 (226 e 214), CpA (30 e 9), CpB (146 e 62), LACK (58 e 57), Histone H1 (13 e 5) e LCR1 (17 e 11). Para as outras proteínas que também estavam inclusas no banco de dados específico não houve similaridade relevante podendo indicar que não se trata de sequencias conservadas nas diferentes espécies de Leishmania. Isso levaria a resultados insatisfatórios porque obteria epítopos restritos a determinada espécie, ou então, são dados que ainda carecem de mais análises comparativas e/ou sequenciamento e anotação dos genes dentre as diferentes espécies que constituem o complexo.

Em relação às informações que obtiveram similaridade desejável pode-se dizer que são plausíveis de indicar que estejam conservadas nas diferentes espécies envolvidas na LV. Deste modo, sendo útil na busca de epítopos em suas estruturas, pois há potencial de se comportarem como antígenos universais devido ao seu caráter imunogênico, abarcar as diferentes amostras de protozoários envolvidos na etiologia da doença.

As sequências de proteínas selecionadas e obtidas após disparo com o Gene DB foram submetidas à ferramenta PHD (figura 1) para predizer a estrutura secundária de proteínas, definindo regiões de alfa-hélice, fita estendida e randômica (tabela 1). Essa ferramenta baseia-se pelo princípio de predição definido como ab-initio, que a partir da sequência de aminoácidos fundamenta-se em leis físicas e moleculares. Tal fenômeno gera a predição do comportamento dos aminoácidos analisados para formar a estrutura proteica secundária. Com exceção da PapLE22 e da LCR1 que tiveram prevalência de alfa-hélices, todas as outras mostraram prevalentes em estruturas randômicas (tabela 1).

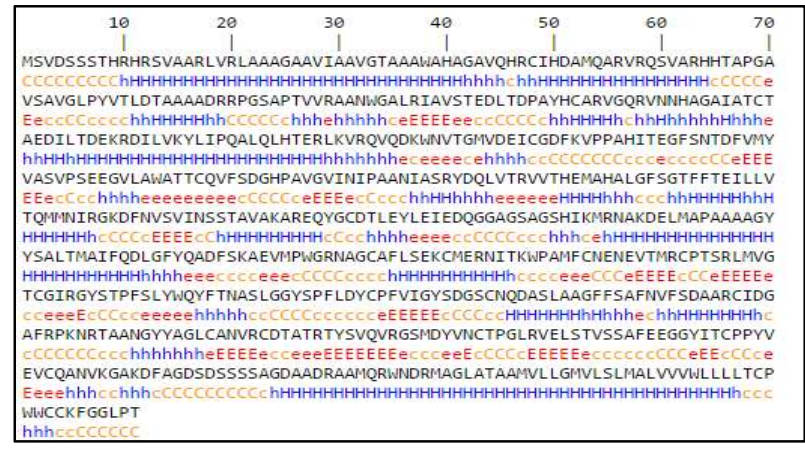

Figura 1: Predição da estrutura secundária da proteína GP63 pela ferramenta PHD, alfa-hélice (azul), fita estendida (vermelha) e randômica (amarela).

\begin{tabular}{|l|r|r|r|}
\hline \multicolumn{1}{|c|}{ PROTEINA } & ALFA-HÉLICE & ESTENDIDA & RANDÓMICA \\
\hline GP63 & $48,67 \%$ & $19,50 \%$ & $31,83 \%$ \\
\hline A2 & 0 & $46,00 \%$ & $54,00 \%$ \\
\hline Tryparedoxin & $29,66 \%$ & $24,83 \%$ & $45,51 \%$ \\
\hline Peroxiredoxin & $26,55 \%$ & $20,80 \%$ & $52,65 \%$ \\
\hline HSP70 & $35,60 \%$ & $17,80 \%$ & $46,60 \%$ \\
\hline Cystein peptidase & $38,11 \%$ & $17,75 \%$ & $44,14 \%$ \\
\hline PapLE22 & $73,10 \%$ & $13,71 \%$ & $13,19 \%$ \\
\hline CPA & $20,62 \%$ & $33,90 \%$ & $45,48 \%$ \\
\hline CPB & $32,73 \%$ & $24,60 \%$ & $42,67 \%$ \\
\hline LACK & $14,74 \%$ & $41,67 \%$ & $43,59 \%$ \\
\hline histone h1 & $19,84 \%$ & $34,52 \%$ & $45,64 \%$ \\
\hline LCR1 & $51,65 \%$ & $6,58 \%$ & $41,77 \%$ \\
\hline \hline
\end{tabular}

Figura 2: Resultado da ferramenta de predição de estrutura secundária PHD.

Visando inferir o potencial antigênico das proteínas selecionadas a ferramenta IEDB Analysis Resource (Figura 3) foi utilizada a partir de cálculos de acessibilidade, antigenicidade, flexibilidade e 
hidrofilicidade chegar a regiões com potencial de se apresentar como um epítopo linear imunogênico. Assim posteriormente pode ser empregado no desenvolvimento de antígenos quiméricos com capacidade de reconhecimento por linfócitos B e, consequentemente, ser um candidato a uso em vacinas. Na predição de acessibilidade uma pontuação máxima de: GP63 (6,965); A2 (4,176); tryparedoxin $(4,610)$; peroredoxin (7,056); HSP70 (5,474); Cystein peptidase (8,062); PapLE22 (8,120); CpA (5,918); CpB (8,929); LACK $(4,565)$; Histone H1 $(4,017)$ e LCR1 $(6,938)$.

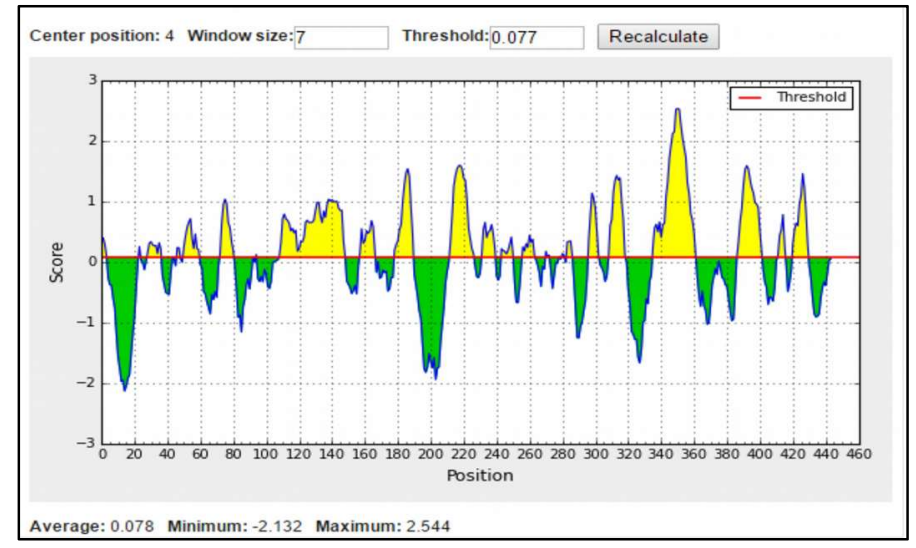

Figura 3: Análise de acessibilidade da proteína CpB pelo IEDB.

Para a predição de antigenicidade: GP63 $(1,256) ;$ A2 $(1,349)$, tryparedoxin $(1,150)$; peroxiredoxin $(1,236)$, HSP70 (1,250); cystein peptidase (1,254), PapLE22 (1,233); CpA $(1,262)$; CpB $(1,342)$; LACK $(1,220)$; Histone H1 (1,331) e LCR1 $(1,242)$. Para a predição de flexibilidade: GP63(1,129), A2 $(1,086)$; tryparedoxin (1,088); peroxiredoxin (1,095); HSP70 (1,129); cystein peptidase (1,109); PapLE22 (1,101); CpA $(1,094)$; CpB (1,138); LACK $(1,089) ;$ histone H1 $(1,103)$ e LCR1 $(1,135)$. Para a predição de Hidrofilicidade: GP63 $(7,500) ;$ A2 $(4,171)$; tryparedoxin $(6,486)$; peroxiredoxin $(6,386) ; \operatorname{HSP70}(7,543)$; cystein peptidase $(7,943)$; PapLE22 (5,829); CpA (6,757); CpB (7,229); LACK $(6,186) ;$ histone H1 $(5,357)$ e LCR1 $(7,171)$. A partir da comparação dos dados acimas foram selecionados epítopos lineares pelo Bepipred do IEDB, que resultou na figura 4.

\begin{tabular}{|c|c|c|c|}
\hline PROTEINA & INICIO & FIM & SEQUENCIA \\
\hline \multirow{2}{*}{ GP63 } & 565 & 597 & ANVKGAKDFAGDSDSSSSAGDAADRAAMQRWND \\
\hline & 513 & 527 & CDTATRTYSVQVRGS \\
\hline \multirow{2}{*}{ A2 } & 123 & 155 & VGPQAVGPQSVGPLSVGPQSVGPLSVGPQSVGP \\
\hline & 89 & 106 & LSVGPQSVGPLSVGPQAV \\
\hline \multirow{2}{*}{ Peroxiredoxin } & & & QYADENGDAIPCGWKPGQPTLDTTKAGEFF \\
\hline & & & VNTPRKKGGLGE \\
\hline \multirow{4}{*}{ HSP70 } & 609 & 628 & KYEADDRAQRDRVEAKNGLE \\
\hline & 637 & 656 & TLGDSNVSGKLDDSDKATLN \\
\hline & 668 & 684 & SNQEATKEEYEHKQKEL \\
\hline & 232 & 247 & YFNDSQRQATKDAGTI \\
\hline \multirow{3}{*}{ PapLE22 } & 63 & 92 & AAAVTKRTIVTSPEDVTASMDRAYESVRPC \\
\hline & 3 & 24 & ALAKEFKGLTTKDVVTWRRPVA \\
\hline & 145 & 169 & APVAYEKKQNEIEHAVQQVRAYADK \\
\hline \multirow{4}{*}{$\mathrm{CPA}$} & 46 & 62 & KKRHGKPFGEDAEEGRR \\
\hline & 186 & 195 & NIDDGCNGGL \\
\hline & 207 & 238 & HNGTVPTEDSYPYTSAGGTRPPCHDNGTVGAK \\
\hline & 244 & 266 & SLPHDEEEIAAYVGKNGPVAVAV \\
\hline \multirow{2}{*}{ СрB } & 108 & 148 & AKQHAGQHYRKARADLSAVPDAVDWREKGAVTPVKNQGACG \\
\hline & 335 & 361 & PVSAHVPRSLTPGPGTESEERAPKRVT \\
\hline \multirow{3}{*}{ histone h1 } & 18 & 39 & RCHAPISSAPRTRVCVGSSSFP \\
\hline & 150 & 164 & CTSEGTPIRDSFQNL \\
\hline & 166 & 175 & RSLAQSYAAM \\
\hline
\end{tabular}

Figura 4: Quadro de peptídeos selecionados como epítopos linear das proteínas de interesse.

Na verificação de afinidade dos epítopos em relação a capacidade de se ligarem a células MHC-II por meio da NethMHCII foi delimitado a utilização de 15 alelos. A ferramenta retorna quando há valores de 
afinidade significativo e o nível de ligação, classificando-as em ligação forte (SB) e ligação fraca (WB). Foi obtido como resultados de ligação forte os seguintes epítopos e as com ligações fracas foram descartadas. A figura 5 traz os grupos GP63, Peroxiredoxin, HSP70, PapLE22, CpA, CpB e Histone H1, respectivamente.

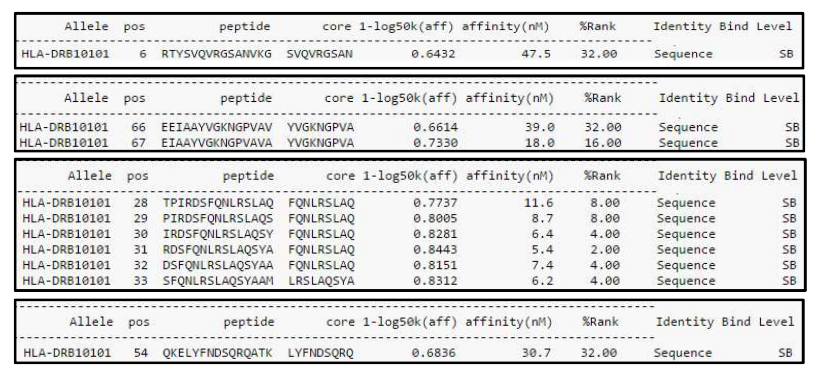

Figura 5: Grupos GP63, Peroxiredoxin, HSP70, PapLE22, CpA, CpB e Histone H1, respectivamente.

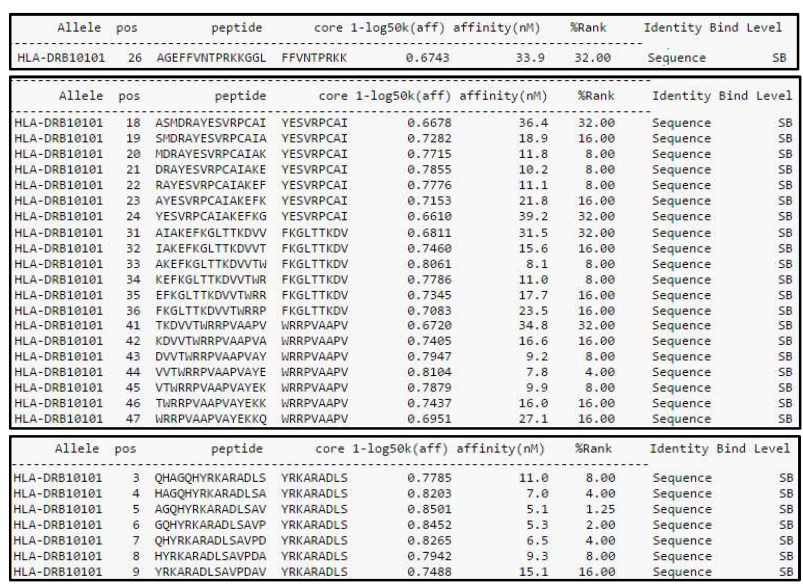

Baseando-se na estrutura secundária, a ferramenta SWISS-MODEL faz a modelagem da estrutura terciária (tridimensional) a partir do método por homologia. Por meio da estrutura terciária de uma proteína já conhecida, o algoritmo realiza comparações para resultar na modelagem tridimensional da proteína de interesse. O conhecimento destas estruturas mais complexas é fundamental, pois serve de alicerce para a identificação de epítopos conformacionais, os quais são maioria de epítopos de linfócitos B. Além disso, carrega informações sobre a complexidade química que refletirão na imunogenicidade. Os modelos retornados pelo SWISS-MODEL, conforme se vê nas figuras 6, 7 e 8 .

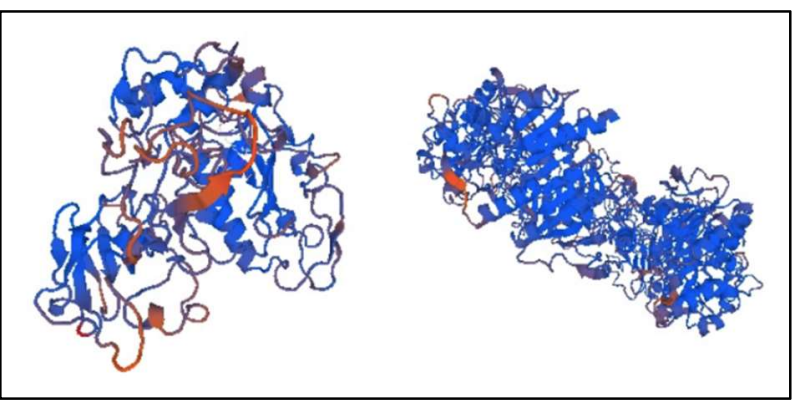

Figura 6: Modelo 3D da proteína GP63 (esquerda) e peroxiredoxin (direita).

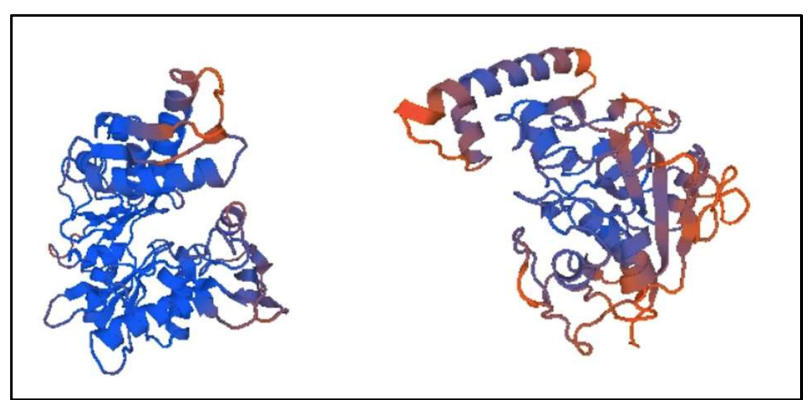

Figura 7: Modelo 3D da proteína HSP70 (esquerda) e CpB (direita).

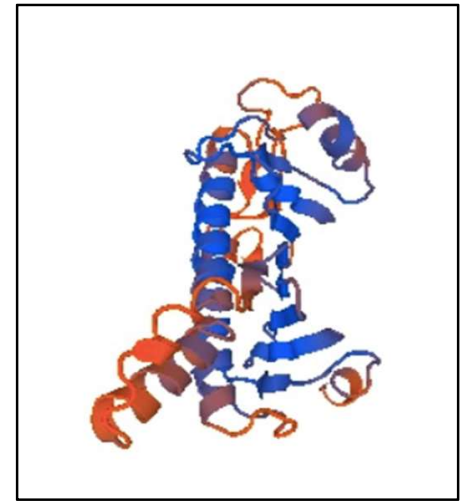

Figura 8: Modelo 3D da histone H1. 
Para verificação da qualidade dos modelos preditos, eles foram submetidos à ferramenta Procheck, disponibilizada em PDBsum_EBI, que realiza comparações com os conteúdos do PDB, e resultaram em resultados gráficos Ramachandran. Para a proteína GP63, foram identificados 126 resíduos (com exceção de glicina e prolina) distribuídos da seguinte forma: $88,1 \%$ em regiões mais favoráveis, $11,1 \%$ em regiões adicionais mais permissivas (figura 9).

Para a proteína peroxiredoxin, foram identificados 1452 resíduos (com exceção de glicina e prolina) distribuídos da seguinte forma: 92,3\% em regiões mais favoráveis, 7,3\% em regiões adicionais mais permissivas (figura 10). Para a proteína HSP70, foram identificados 338 resíduos (com exceção de glicina e prolina) distribuídos da seguinte forma: $88,8 \%$ em regiões mais favoráveis, $35 \%$ em regiões adicionais mais permissivas, $0,9 \%$ regiões permissivas (figura 11 ).

Para a proteína $\mathrm{CpB}$, foram identificados 265 resíduos (com exceção de glicina e prolina) distribuídos da seguinte forma: $84,2 \%$ em regiões mais favoráveis, $13,6 \%$ em regiões adicionais mais permissivas, $0,4 \%$ regiões permissivas e 1,9\% em não permissivas (figura 12). Para a proteína histone $\mathrm{H} 1$ foram identificados 207resíduos (com exceção de glicina e prolina) distribuídos da seguinte forma: $85,5 \%$ em regiões mais favoráveis, $10,6 \%$ em regiões adicionais mais permissivas, $2,4 \%$ regiões permissivas e $1,4 \%$ em não permissivas (figura 13).

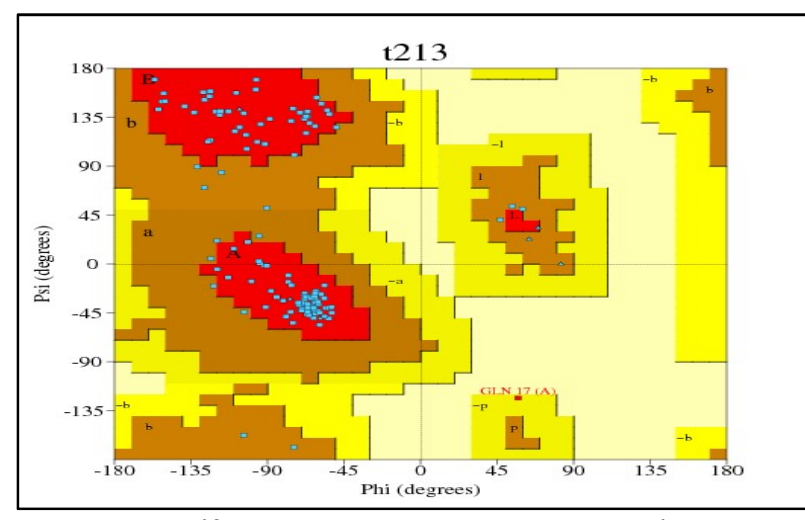

Figura 9: Gráfico de Ramachandran para a proteína GP63, região mais favorável $(A, B, L)$, adicionais mais permissivas $(a$, b, l), permissivas ( $\sim a, \sim b, \sim 1, \sim p$ ) e não permissivas (bege), quadrados azuis significam a distribuição dos resíduos.

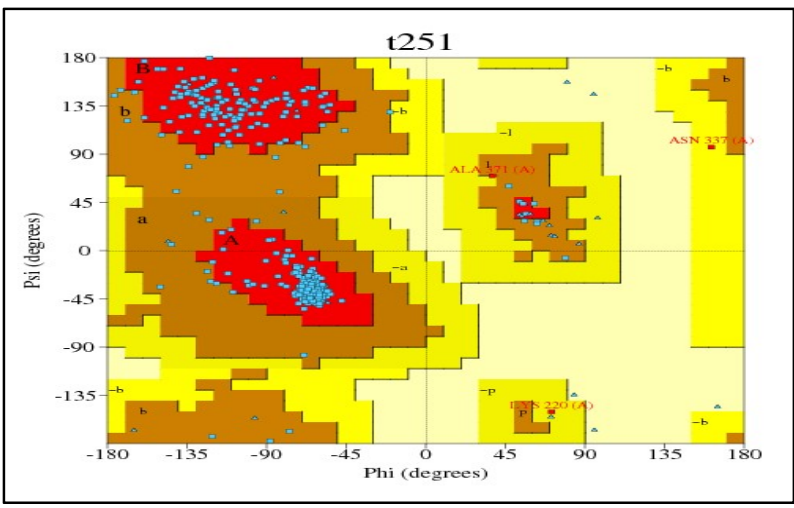

Figura 11: Gráfico de Ramachandran para a proteína HSP70, região mais favorável $(A, B, L)$, adicionais mais permissivas $(a$, $b$, I), permissivas ( $\sim a, \sim b, \sim 1, \sim p$ ) e não permissivas (bege), quadrados azuis significam a distribuição dos resíduos.

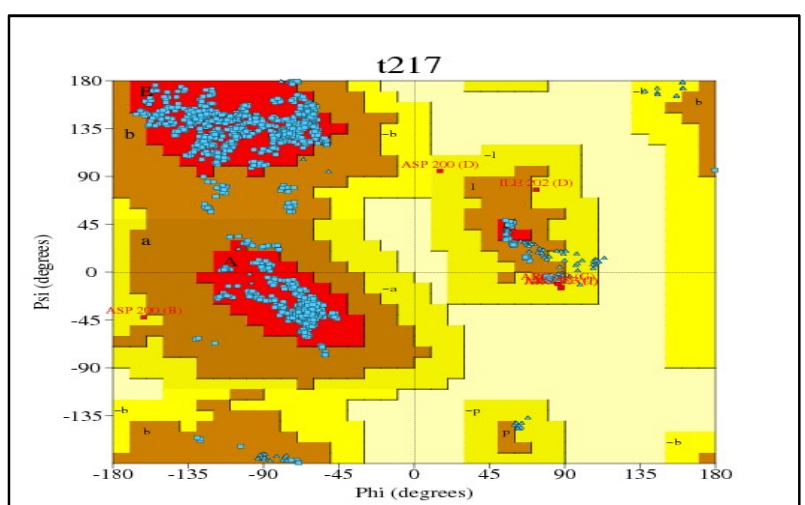

Figura 10: Gráfico de Ramachandran para a proteína peroxiredoxin, região mais favorável $(A, B, L)$, adicionais mais permissivas $(a, b, l)$, permissivas $(\sim a, \sim b, \sim I, \sim p)$ e não permissivas (bege), quadrados azuis significam a distribuição dos resíduos.

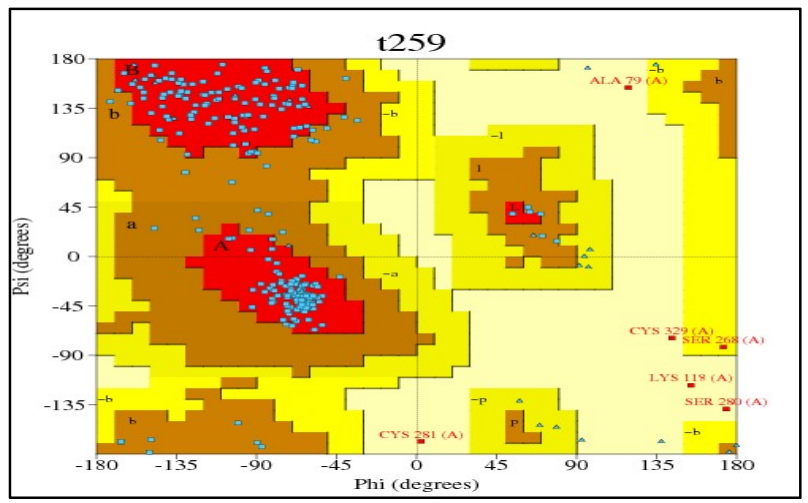

Figura 12: Gráfico de Ramachandran para a proteína $C p B$, região mais favorável $(A, B, L)$, adicionais mais permissivas ( $a$, b, l), permissivas ( a, b, I, p) e não permissivas (bege), quadrados azuis significam a distribuição dos resíduos. 


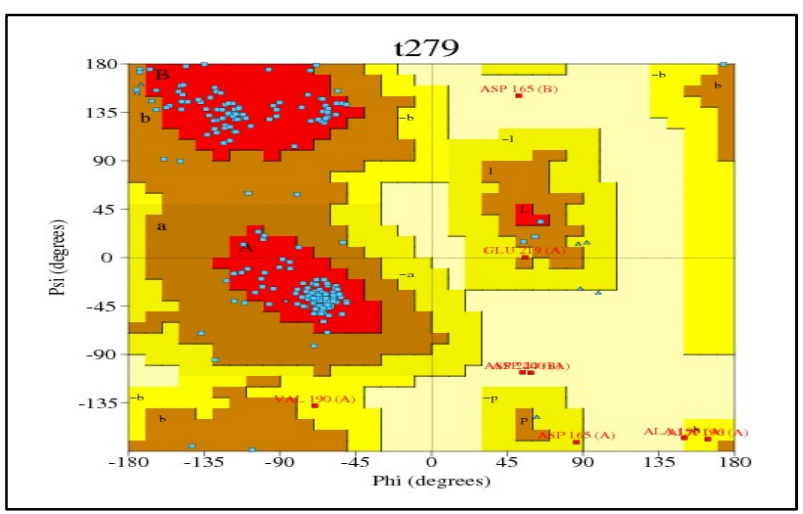

Figura 13: Gráfico de Ramachandran para a proteína histone $H 1$, região mais favorável $(A, B, L)$, adicionais mais permissivas $(a, b, l)$, permissivas ( $a, \sim b, \sim 1, \sim p)$ e não permissivas (bege), quadrados azuis significam a distribuição dos resíduos.

\section{DISCUSSÃO}

Por meio dos alinhamentos de sequências por algoritmos BLAST, tornou-se possível obter sequências conservadas de diferentes espécies de Leishmania. Estas relacionadas com a leishmaniose visceral. Apresentando sequencias representativas ao serem disparadas contra o banco de dados GenBank e demonstrando altos índices de similaridade. Tais informações foram representativas de proteínas consideradas potencialmente imunogênicas. A análise in silico das proteínas elegidas tornou capaz a predição de epítopos lineares que computacionalmente apresentaram-se relevantes por servirem de alicerce na identificação de antígenos capazes de disparar resposta imunogênica ao se ligarem a linfócitos B humanos e produzir células de memórias. Esse cenário é desejável ao se buscar fragmentos proteicos candidatos à elaboração de vacinas.

Neste estudo as proteínas que alcançaram resultados das análises in silico mais desejáveis foram a: GP63, peroxiredoxin, HSP70, CpB e Histone H1. Sabendo-se que a maioria dos epítopos de linfócitos B são conformacionais, foi realizada a modelagem comparativa da estrutura terciária destas proteínas que apresentaram representatividade aceitável segundo os diagramas de Ramachandran. Porém estas carecem de maiores estudos a partir da sua estrutura tridimensional para se chegar na predição dos epítopos conformacionais.

\section{CONCLUSÕES}

As proteínas que não conseguiram atingir as perspectivas mínimas na obtenção de antígenos de interesse não devem ser descartadas, pois podem ser submetidas a outras ferramentas e metodologias de bioinformática. Os resultados in silico por meio das possibilidades de predições e simulações apresentam boa confiabilidade, agilidade na obtenção das informações e são feitos por um método barato. Porém, é importante destacar que a confiabilidade destes resultados carece de experimentos em bancadas.

\section{REFERÊNCIAS}

ARAÚJO, N. D.. A era da bioinformática: seu potencial e suas aplicações para as ciências da saúde. Estudos de Biologia, v.30, n.70, p.1473-148, 2008.
ARBEX, W.; SILVA, M. V. G. B. D.; COSTA, V. M. M. S.. Bioinformática como ferramenta nas pesquisas atuais. In: ENCONTRO DE GENÉTICA E MELHORAMENTO DA UNIVERSIDADE FEDERAL DE VIÇOSA, 3. Anais. Viçosa: 2006. 
BINNECK, E.. As ômicas: integrando a bioinformação.

Biotecnologia, Ciência e Desenvolvimento, Londrina, n.32, p.28-37, 2004.

FREIRE, C. C. M.; LOBO, L. T. C.; XIMENES, M. F. F. M.. Uma abordagem da bioinformática na avaliação de especificidade de antígenos utilizados em ensaios imunoenzimáticos para diagnóstico da Leishmaniose visceral. Revista Brasileira de Análises Clínicas, Natal, v.41, n.2, p.139-142, 2009.

LESK, A. M.. Introdução à Bioinformática. Porto Alegre: Artmed, 2007.

PINTO, E. F.; MATTA, N. E.; CRUZ, A. M.. Vacinas: progressos e novos desafios para o controle de doenças imunopreveníveis. Acta Biológica Colombiana, v.16, n.3, p.197-212, 2011.

PROSDOCIMI, F.; COUTINHO, G.; NINNECW, E.; SILVA, A. F.; REIS, A. N.; MARTINS, A. C.; CAMARGO FILHO, F..
Bioinformática: Manual do Usuário. Biotecnologia Ciência \& Desenvolvimento, n.29, 2002.

PROSDOCIMI, F.; SANTOS, F. R.. Sobre informática, genômica e ciência. Ciência Hoje, Belo Horizonte, v.35, n.209, p.54-57, 2004.

SANTOS, F. R.; ORTEGA, J. M.. Bioinformática aplicada à Genômica. Belo Horizonte: 2003.

SANTOS, R. T.; DUARTE, A. A.. Desenvolvimento de métodos de bioinformática para busca in-silico de epítopos T CD8+ humanos no proteoma da leishmania braziliensis. Salvador: 2013.

TEUFEL, A.; KRUPP, M.; WEINMANN, A.; GALLE, P. R.. Current bioinformatics tools in genomic biomedical research. International Journal of Molecular Medicine, v.17, n.6, p.967-973, 2006.

VERLI, H.. Bioinformática: da biologia à flexibilidade molecular. Porto Alegre, 2014.

A CBPC - Companhia Brasileira de Produção Científica (CNPJ: 11.221.422/0001-03) detém os direitos materiais desta publicação. Os direitos referem-se à publicação do trabalho em qualquer parte do mundo, incluindo os direitos às renovaç̃oses, expansões e disseminações da contribuiç̃o, bem como outros direitos subsidiários. Todos os trabalhos publicados eletronicamente poderão posteriormente ser publicados em coletâneas impressas sob coordenação da Sustenere Publishing, da Companhia Brasileira de Produção Científica e seus parceiros autorizados. Os (as) autores (as) preservam os direitos autorais, mas não têm permissão para a publicação da contribuição em outro meio, impresso ou digital, em português ou em tradução. 